Stephen Raftery MB BCh BAO FFARCSI, Eoin Sherry MB BCh BAO FCAnucs FFARCSI

\title{
Total intravenous anaesthesia with propofol and alfentanil protects against postoperative nausea and vomiting
}

The incidence of postoperative nausea and vomiting and requirements for anti-emetic medication were assessed in 80 female patients undergoing day-case anaesthesia during assisted conception therapy. Anaesthesia was induced with alfentanil $50 \mu \mathrm{g} \cdot \mathrm{kg}^{-1}$ and propofol $1 \mathrm{mg} \cdot \mathrm{kg}^{-1}$; atracurium $0.5 \mathrm{mg} \cdot \mathrm{kg}^{-1}$ was given to facilitate tracheal intubation. The patients were allocated to receive either total intravenous maintenance of anaesthesia with an infusion of propofol and increments of alfentanil (Group $P$ ) or inhalational maintenance of anaesthesia with nitrous oxide and enflurane (Group E). Postoperative nausea, retching, vomiting, requirements for anti-emetic therapy, and unplanned admission for overnight stay in hospital were recorded. Overall incidence of nausea was $64 \%$ in group $E$ and $39 \%$ in Group $P(P<0.05)$. Incidence of vomiting was $67 \%$ in Group E and 34\% in Group $P(P<0.05)$. Metoclopramide was requested by $62 \%$ of patients in Group $E$, and $32 \%$ of those in Group $P(P<0.05) ; 21 \%$ of the patients in Group $E$ were admitted to hospital overnight, while only $5 \%$ of the patients in Group $P$ required unscheduled admission to hospital $(P<0.05)$. We conclude that total intravenous anaesthesia with propofol and alfentanil is superior to inhalational maintenance with

\section{Key words}

ANAESTHETIC: outpatient;

ANAESTHETIC TECHNIQUES: intravenous;

ANAESTHETICS, GASES: nitrous oxide;

ANAESTHETICS, INTRAVENOUS: alfentanil, propofol;

ANAESTHETICS, VOLATILE: enflurane;

VOMITING: Nausea.

From the Sir Humphry Davy Department of Anacsthesia, Bristol Royal Infirmary, Bristol, BS2 8HW, UK.

Address correspondence to: Dr. S. Raftery, Department of

Anaesthesia, Derriford Hospital, Plymouth, PL6 8DH, UK.

Presented in part to the Association of Anaesthetists of

Great Britain and Ireland, Manchester, September 1990.

Accepted for publication 12th August, 1991. nitrous oxide and enflurane in that it is associated with less nausea and vomiting, less requirement for anti-emetic medication, and a lower probability of unplanned admission to hospital after day-care gynaecological surgery.

L'incidence de nausées et vomissements en période postopératoire et le besoin de médication antiérnétique a été évalué chez 80 patientes devant subir une anesthésie (cas d'un jour) pendant une séance de conception assistée. L'induction de l'anesthésie $s$ 'est faite à l'aide d'alfentanil $50 \mu g \cdot \mathrm{kg}^{-1}$ et de propofol $I \mathrm{mg} \cdot \mathrm{kg}^{-1}$; l'intubation endotrachécale a été facilitée à l'aide d'atracurium $0,5 \mathrm{mg} \cdot \mathrm{kg}^{-1}$. L'anesthésie érait maintenue soir à l'aide d'une technique intraveineuse totale, en utilisant une infusion de propofol et des bolus d'alfentanil (groupe $P$ ). soit à l'aide d'une technique d'inhalation en utilisant le protoxyde d'azote et l'enflurane (groupe E). Pendant la période postopératoire, les nausées, les efforts de vomissement, les vomissements, le besoin de thérapie antiémétique, et les admissions hospitalières imprévues pour une nuit étaient notés. $L$ 'incidence globale de nausées était de $64 \%$ dans le groupe $E$ et $39 \%$ dans le groupe $P(P<0,05)$. L'incidence de vomissements était de $67 \%$ dans le groupe E et de $34 \%$ dans le groupe $P(P<0,05)$. Soixante-deux pourcent des patientes du groupe $E$ ont demandé du métoclopramide, comparativement à $32 \%$ du groupe $P(P<0.05) ; 21 \%$ des patientes du grope $E$ ont été admises à l'hôpital pour une nuit, tandis que seulement $5 \%$ des patientes du groupe Pl'ont été $(P<0,05)$. Nous concluons que l'anesthésie à l'aide d'une technique intraveineuse totale, avec propofol et alfentanil, est supérieure à une anesthésie par inhalation à l'aide de protoxyde d'azote et d'enflurane car elle est associée à une incidence moins élevée de nausées et vomissements, un besoin moindre de médication antiémétique, et une probabilité plus faible d'admissions hospitalières imprévues après une chirurgie gynécologique d'un jour.

Nausea and vomiting are common symptoms after inhalational general anaesthesia. ${ }^{1-4}$ It is possible that the 
anaesthetic technique may influence these symptoms, although many other factors such as sex and a susceptibility to motion sickness may also be involved.

This study was performed to determine whether total intravenous anaesthesia with propofol and alfentanil reduced the incidence of nausea and vomiting and requirements for anti-emetic therapy after gynaecological surgery of intermediate duration. We also wished to test whether this anaesthetic technique may be associated with a lower probability of unplanned admission to hospital after outpatient gynaecological surgery.

\section{Methods}

The project was approved by the District Health Authority Ethical Committee. Eighty healthy women scheduled for outpatient laparoscopic or ultrasound-guided oocyte harvesting for in vitro fertilisation (IVF) or laparoscopic gamete intra-Fallopian transfer (GIFT) were studied. Informed consent was obtained in each case. The patients were informed that although they would not be given prophylactic anti-emetic drugs, these would be available and would be given if requested.

The patients' history of emetic symptoms after previous general anaesthesia was elicited. Age, weight and serum oestradiol concentration were recorded. Patients were allocated according to their history of previous nausea into one of two groups, labelled $E$ and $P$. Anaesthesia was induced in all patients with alfentanil $50 \mu \mathrm{g} \cdot \mathrm{kg}^{-1}$ and propofol $1 \mathrm{mg} \cdot \mathrm{kg}^{-1}$. Atracurium $0.3 \mathrm{mg} \cdot \mathrm{kg}^{-1}$ was given to facilitate tracheal intubation and ventilation of the lungs. In Group E, anaesthesia was maintained by enflurane $1-2 \%$ with $70 \%$ nitrous oxide in oxygen. In Group P, anaesthesia was maintained by an infusion of propofol 10 $\mathrm{mg} \cdot \mathrm{kg}^{-1} \cdot \mathrm{hr}^{-1}$ for ten minutes, $8 \mathrm{mg} \cdot \mathrm{kg}^{-1} \cdot \mathrm{hr}^{-1}$ for a further ten minutes, and $6 \mathrm{mg} \cdot \mathrm{kg}^{-1} \cdot \mathrm{hr}^{-1}$ subsequently, and increments of alfentanil up to a maximum of 50 $\mu \mathrm{g} \cdot \mathrm{kg}^{-1} \cdot \mathrm{hr}^{-1}$ as clinically indicated. ${ }^{5,6}$ The lungs were ventilated with air and oxygen. A Penlon-Oxford ventilator was used with anaesthetic gases or oxygen supplied to the gas inlet at a rate calculated to produce an $\mathrm{FiO}_{2}$ of 0.3 and normal $\mathrm{FETCO}_{2}$ in all cases. The infusion of propofol was delivered using a calibrated Ohmeda 9000 infusion pump. The ECG, heart rate, blood pressure, and arterial oxygen saturation were monitored throughout the procedure. Further increments of atracurium were given only if the surgeon requested abdominal relaxation.

The surgical management of the patients having laparoscopy and GIFT was similar except that after laparoscopic oocyte harvesting, a gas drain was inserted into the peritoneal cavity to aid elimination of carbon dioxide, and this was omitted in the GIFT patients. Ultrasound-guided oocyte harvesting was done by the vaginal route and these patients did not have laparoscopy or $\mathrm{CO}_{2}$ insufflation.

At the end of surgery, residual muscle relaxation was
TABLE I Age, weight, scrum concentration of oestradiol, duration of anaeschesia and time to arousal from anaesthesia for patients in both groups. Results arc expressed as mean (SD). There was no significant difference between groups

\begin{tabular}{lll}
\hline & $E$ & $P$ \\
\hline$n$ & 39 & 41 \\
Age, $\mathrm{yr}$ & $34.7(5.9)$ & $34.8(4.4)$ \\
Weight, $\mathrm{kg}$ & $62.6(9.8)$ & $61.8(9.4)$ \\
Oestradiol, $\mathrm{pmol} \cdot \mathrm{L}^{-1}$ & $6031(3095)$ & $6272(3157)$ \\
Duration, min & $75.1(26.3)$ & $70.5(22.7)$ \\
Arousal, min & $9.3(5.0)$ & $7.8(4.4)$ \\
\hline
\end{tabular}

reversed with neostigmine $2.5 \mathrm{mg}$ and glycopyrrolate 0.5 $\mathrm{mg}$ only if the patient had been given a second or subsequent increment of atracurium. The infusion or vapour was stopped and the lungs ventilated with oxygen until the patient was awake, when the tracheal tube was removed. Total anaesthesia time, and time from stopping the anaesthetic until the patient could repeat her date of birth, were recorded. Metoclopramide $10 \mathrm{mg}$ im was prescribed for postoperative nausea if requested by the patient. Oral analgesic agents were prescribed for postoperative pain.

In the postoperative phase, patients were assessed by trained recovery and ward nurses, who were not aware of the anaesthetic technique, with regard to symptoms of nausea. Patients were asked how they felt and whether they were comfortable, they were not specifically asked about nausea unless this was spontaneously volunteered. Patients were observed for retching or vomiting, and if metoclopramide was requested for relief of symptoms this was administered and recorded. These symptoms were classified according to whether they occurred up to $30 \mathrm{~min}$ after cessation of anaesthesia, between $30 \mathrm{~min}$ and two hours, and between two and six hours postoperatively. Staff performing the assessments were unaware of the anaesthetic used. Patients were discharged home six hours after anaesthesia, unless they requested admission overnight. The decision to admit the patient was taken by the patient in consultation with the surgeon; the anaesthetist involved was not consulted.

The proportion of patients complaining of nausea, retching or vomiting, the proportion given metoclopramide, and the proportion admitted overnight to hospital were tested using a chi-squared $\left(x^{2}\right)$ test with Yates' continuity correction; Fisher's exact test (two-tailed) was used instead if any of the cells had expected counts less than five. Demographic data were analysed using Student's unpaired $t$ test. $P<0.05$ was taken to indicate statistical significance.

\section{Results}

Patients in both groups were similar in terms of age, weight, serum concentration of oestradiol, duration of 
TABLE II Type of operation and history of nausea after previous anaesthesia

\begin{tabular}{lll}
\hline & $E$ & $P$ \\
\hline Operation & & \\
Laparoscopy for IVF & 22 & 26 \\
Ultrasound for IVF & 7 & 7 \\
GIFT & 10 & 8 \\
History of nausea & & \\
Yes & 16 & 17 \\
No & 23 & 24 \\
\hline
\end{tabular}

anaesthesia and time to waken (Table I). The numbers of patients who had laparoscopy, GIFT, or ultrasound collection of oocytes, and the numbers who elicited a history of nausea or vomiting after previous anaesthesia were similarly distributed between the two groups (Table II).

Patients in Group E were more likely than those in Group $P$ to have all the symptoms of nausea, retching, or vomiting during the first $\mathbf{3 0}$ minutes after anaesthesia (Table III). Similarly, they were more likely to have symptoms at some time during the entire study period. However, comparisons made after two hours and six hours did not reveal a significant difference between the two groups.

Patients in Group E requested metoclopramide for relief of postoperative nausea or vomiting more often than those in Group P. Unplanned admissions to hospital were more common in Group E than in Group P (Table IV).

\section{Discussion}

Nausea and vomiting are common symptoms after anaesthesia. Although they are often regarded as of minor importance in terms of serious consequences, they are distressing to patients, particularly for those undergoing elective surgery in an out-patient unit. In addition, it is possible for patients to aspirate gastric contents if they vomit before complete recovery of airway protective reflexes. In the interests of both safety and patient comfort it is important to alleviate these symptoms.

Nitrous oxide has been implicated in the genesis of postanaesthetic nausea and vomiting. Postulated mechanisms are the diffusion of nitrous oxide into the middle ear where the excess pressure distorts the fenestra rotunda and thereby affects the vestibular apparatus. ${ }^{8}$ Nitrous oxide may also diffuse into the stomach and colon, causing them to distend and leading to retching, vomiting, and abdominal discomfort in the postoperative period. ${ }^{9}$ Other factors that may be involved include young age and female sex, ${ }^{10}$ particularly during menstruation, ${ }^{11}$ and after laparoscopy. ${ }^{2}$ This may be due to gas remaining within the abdominal cavity after inadequate deflation of the perito-
Table III Number (\%) of patients in each group who experienced adverse symptoms during recovery from anaesthesia

\begin{tabular}{lll}
\hline & $E$ & $P$ \\
\hline$n$ & $39(100 \%)$ & $41(100 \%)$ \\
Up to 30 min & & \\
Nausea & $18(46 \%)$ & $3(7 \%)^{*}$ \\
Retching & $16(41 \%)$ & $1(2 \%)^{*}$ \\
Vomiting & $20(51 \%)$ & $3(7 \%)^{*}$ \\
30 min to $2 h r$ & & \\
Nausea & $17(44 \%)$ & $13(32 \%)$ \\
Retching & $7(18 \%)$ & $4(10 \%)$ \\
Vomiting & $9(23 \%)$ & $11(27 \%)$ \\
& & \\
2 to 6 hr & & \\
Nausca & $8(21 \%)$ & $7(17 \%)$ \\
Retching & $5(13 \%)$ & $0(0 \%)^{*}$ \\
Vomiting & $7(18 \%)$ & $3(7 \%)$ \\
& & \\
Overall & & $16(39 \%)^{*}$ \\
Nausea & $25(64 \%)$ & $4(10 \%)^{*}$ \\
Retching & $18(46 \%)$ & $14(34 \%)^{*}$ \\
Vomiting & $26(67 \%)$ & \\
\hline
\end{tabular}

${ }^{*} P<0.05, \chi^{2}$ test.

$\dagger P<0.05$, Fisher exact test.

TABLE IV Number (\%) of patients in each group given meloclopramide after anaesthesia, and number of those who were admitted to hospital overnight

\begin{tabular}{lll}
\hline & $E$ & $P$ \\
\hline$n$ & $39(100 \%)$ & $41(100 \%)$ \\
Metoclopramide & & \\
$<30$ minutes & $18(46 \%)$ & $2(5 \%)^{*}$ \\
$1 / 2-2$ hours & $6(15 \%)$ & $8(20 \%)$ \\
$2-6$ hours & $5(13 \%)$ & $5(12 \%)$ \\
Overall & $24(62 \%)$ & $13(32 \%)^{*}$ \\
Overnight admission & $8(21 \%)$ & $2(5 \%) \dagger$ \\
\hline
\end{tabular}

${ }^{*} P<0.05, \chi^{2}$ test.

$\dagger P<0.05$, Fisher exact test.

neum. However, some studies have failed to demonstrate a higher incidence of nausea and vomiting with nitrous oxide. $^{12.15}$ In addition there is a population of patients with a greater susceptibility to nausea regardless of anaesthetic technique; these patients also may have a history of motion sickness ${ }^{4}$ or of nausea after previous surgery. ${ }^{10}$

Alfentanil is $\mu$-receptor agonist, and would be expected to induce nausea and vomiting in common with other $\mu$-agonists such as morphine or meperidine. Our Group E patients received a single dose of alfentanil at induction of anaesthesia, whereas those in Group $P$ received additional doses up to $50 \mu \mathrm{g} \cdot \mathrm{kg}^{-1} \cdot \mathrm{hr}^{-1}$. This higher dose of opioid was, surprisingly, not associated with a higher incidence of nausea and vomiting. These results suggest that the dose 
of opioid used is not relevant in the genesis of postoperative nausea and vomiting, possibly because of the short half-life of alfentanil. Propofol has been reported to be associated with a lower likelihood of nausea and vomiting after surgery of short duration. ${ }^{13-14}$

There is a wide range of anti-emetic agents available, acting by different mechanisms, and with varying effectiveness. Administering any parenteral medication involves an extra workload on the nursing staff, and introduces an element of risk, albeit small, of incorrect drug, dosage, or administration technique. For these reasons, it is preferable to avoid the need for a parenteral drug.

Total intravenous anaesthesia using propofol and alfentanil avoids many of the problems of inhalational anaesthesia, such as pollution of the operating theatre atmosphere and symptoms due to the physical properties of anaesthetic gases. In our experience this anaesthetic technique leads to rapid awakening, recovery of airway reflexes, and return to street fitness. We wished to test the hypothesis that an anaesthetic technique excluding any anaesthetic gases or vapours may improve patient well-being in the immediate and short-term postoperative period, and may reduce the amount of nursing activity in caring for these patients.

The study population described in this report was homogeneous in that the patients were all of a similar age, all in the middle of their menstrual cycle, and having similar operations of moderate duration. It was not possible to blind the anaesthetist to the anaesthetic agents, but the postoperative assessments were made by nursing staff who were not aware of the anaesthetic technique used, and the decision to admit the patient overnight was not influenced by anaesthetic technique. The patients were all nursed in the same postoperative ward. Nausea is a subjective symptom and as such is very difficult to assess: we simply allowed the patients to complain spontaneously of nausea in response to a non-directive inquiry as to how they felt, and if they wished, metoclopramide was given.

Our results support the contention that inhalational maintenance of anaesthesia with nitrous oxide and enflurane is associated with a higher incidence of nausea than intravenous anaesthesia with propofol and alfentanil. One patient who was considered susceptible to postoperative nausea entered the study twice, the first time receiving inhalational anaesthesia and intravenous the second time; she afterwards expressed a strong preference for intravenous anaesthesia!

Our results show that total intravenous anaesthesia is associated with less postoperative nausea and vomiting, less requirement for postoperative anti-emetic medication, and a lower likelihood of unplanned admission to hospital due to postoperative symptoms.

\section{Acknowledgements}

We wish to acknowledge the recovery and ward nursing staff of the BUPA Hospital Bristol, and ICI (UK) for kindly donating the infusion pump.

\section{References}

1 Alexander GD, Skupski JN, Brown EM. The role of nitrous oxide in postoperative nausea and vomiting. Anesth Analg 1984, 63: 175.

2 Lonie DS, Harper NJN. Nitrous oxide anaesthesia and vomiting: the effect of nitrous oxide anacsthesia on the incidence of vomiting following gynaecological laparoscopy. Anaesthesia 1986, 41: 703-6.

3 Melnick BM. Johnson LS. Effects of eliminating nitrous oxide in outpatient anesthesia. Anesthesiology 1987; 67: 982-4.

4 Kamath B, Curan J, Hawkey C et al. Anacsthesia, movement and emesis. Br J Anaesth 1990; 64: 728-30.

5 Roberts FL, Dixon J, Lewis GTR, Tackley RM, PrysRoberts $C$. Induction and maintenance of propofol anaesthesia. A manual infusion schemc. Anaesthesia 1988; 43: 14-17S

6 Richards MJ, Skues MA, Jarvis AP, Prys-Roberts C. Total intravenous anaesthesia with propofol and alfentanil: dose requirements for propofol and the effect of premedication with clonidine. Br J Anaesth 1990; 65: 157-63.

7 Bellville JW, Bross IDJ, Howland WS. A method for the clinical evaluation of antiemetic agents. Ancsthesiology 1959; 20: 753-9.

8 Davis I, Moore JRM, Sahiri SK. Nitrous oxide and the middle ear. Anaesthesia, 1979; 34: 147-51.

9 Palazzo MGA, Strunin L. Anaesthesia and emesis. I: Etiology. Can Anaesth Soc J 1984; 31: 178-87.

10 Muir JJ, Warner MA, Offord KP, Buck CF, Harper JV, Kunkel SE. Role of nitrous oxide and other factors in postoperative nausea and vomiting: a randomised and blinded prospective study. Anesthesiology 1987; 66: 513-8.

11 Beartie WS, Buckley DN, Forrest JB. The incidence of postoperative nausea and vomiting in women undergoing laparoscopy is influenced by the day of menstrual cycle. Can J Anaesth 1991; 38: 298-302.

12 Korttila $K$, Hovorka J, Erkola $O$. Nitrous oxide does not increase the incidence of nausea and vomiting after isoflurane anesthesia. Anesth Analg 1987; 66: 761-5.

13 Clarke RSJ. Nausea and vomiting. Br J Anaesth 1984; 56: 16-27.

14 Gunawardene RD, White DC. Propofol and emesis. Anaesthesia 1988; 43 (Supplement): 65-7.

15 Hovorka J, Kortila $K$. Nitrous oxide does not increase nausea and vomiting following gynaecological laparoscopy. Can J Anaesth 1989; 36: 145-8. 